\title{
Peacebuilding in times of COVID-19: risk-adapted strategies of cooperation and development projects
}

\author{
Luca Eufemia · Camilo Lozano - Tatiana Rodriguez $\cdot$ Martha Del \\ Rio $\cdot$ Héctor Morales-Muñoz $\cdot$ Michelle Bonatti $\cdot$ Stefan Sieber • \\ Katharina Löhr
}

Received: 10 August 2020 / Revised: 10 August 2020 / Accepted: 18 September 2020 / Published online: 4 November 2020

(C) The Author(s) 2020

\begin{abstract}
National and international cooperation and development projects (CDP) are fundamental for peacebuilding. However, unforeseen global crises, like COVID19, can endanger such projects, requiring rapid adaption. In Colombia, the coronavirus outbreak threatens to slow the implementation of peace-related projects, while simultaneously violence over control and ownership of land increases. Although the mid- to long-term consequences for peacebuilding are unknown, exploring riskadapted strategies of national and international CDP can help identify crucial aspects for future processes and implementations. This study explores the key challenges and coping strategies of implementing agencies and stakeholders to COVID-19, thus helping to derive and improve risk-adapted strategies. After reviewing academic and grey literature, and implementing a semi-structured survey, peacebuilding riskedadapted strategies to COVID-19 are explored with respect to conflict-affected and vulnerable areas of Colombia. Findings show that increasing complexity rooted in top down governmental measures, the rise of new local power relations (e.g. armed groups, illicit activities), and social alienation are negatively affecting peacebuilding
\end{abstract}

\footnotetext{
L. Eufemia $\cdot$ C. Lozano - T. Rodriguez $\cdot$ M. Del Rio $\cdot$ H. Morales-Muñoz $\cdot$ M. Bonatti $\cdot$ S. Sieber $\cdot$ K. Löhr $(\bowtie)$ 
in Colombia. Future CDP risk adapted strategies should build on local interests and needs through public-private and environmental cooperation.

Keywords Pandemic · Conflict · Peacebuilding · Risk-adapted strategies · Cooperation

\section{Friedensförderung in Zeiten von COVID-19: Risikoadaptierte Strategien von Kooperations- und Entwicklungsprojekten}

Zusammenfassung Nationale und internationale Kooperations- und Entwicklungsprojekte (CDP) sind für die Friedensförderung von grundlegender Bedeutung. Unvorhergesehene globale Krisen, wie COVID-19, können solche Projekte jedoch gefährden und erfordern eine rasche Anpassung. In Kolumbien droht der Ausbruch des Coronavirus die Durchführung friedensbezogener Projekte zu verlangsamen, während gleichzeitig die Gewalt über die Kontrolle und den Besitz von Land zunimmt. Obwohl die mittel- bis langfristigen Folgen für die Friedenskonsolidierung unbekannt sind, kann die Untersuchung risikoangepasster Strategien des nationalen und internationalen CDP dazu beitragen, entscheidende Aspekte für künftige Prozesse und Implementierungen zu ermitteln. Diese Studie untersucht die Herausforderungen und Bewältigungsstrategien der Durchführungsorganisationen und Interessengruppen im Kontext von COVID-19, umso risikoangepasste Strategien abzuleiten und zu verbessern. Basierend auf Literaturrecherche und der Durchführung semistrukturierter Interviews werden risikoangepasste Strategien der Friedensförderung für COVID-19 in unterschiedlichen Teilen Kolumbiens untersucht. Die Ergebnisse zeigen, dass die zunehmende Komplexität, die in den Maßnahmen der Regierung von oben nach unten, dem Entstehen neuer lokaler Machtverhältnisse (z. B. bewaffnete Gruppen, illegale Aktivitäten) und in zunehmend sozialer Entfremdung wurzelt, die Friedensförderung in Kolumbien negativ beeinflusst. Künftige risikoangepasste Strategien des CDP sollten auf lokalen Interessen und Bedürfnissen durch öffentlichprivate und umweltpolitische Zusammenarbeit aufbauen.

Schlüsselwörter Pandemie $\cdot$ Konflikt $\cdot$ Friedensbildung $\cdot$ Risikoadaptierte Strategien · Kooperation

\section{Introduction}

National and international cooperation and development projects (CDP) play a fundamental role in peacebuilding processes (Fischhendler and Tenenboim-Weinblatt 2019; Amego Korbla Penu and Wellington Essaw 2019; Lemon and Pinet 2018; Jaruma 2013). Managing CDPs, challenging under normal circumstances, requires agility and flexibility when confronting unforeseen global emergencies, like the outbreak of coronavirus (COVID-19). Without rapidly adapting management approaches, CDP might be endangered. UNDP (2020) notes the impact of COVID-19 is likely to be worse in conflict-affected countries, where past and present vulnerabilities in health and governance could be amplified, thus exacerbating violence. 
Further, seven of the ten most-vulnerable countries to pandemics are in conflict zones (Moore et al. 2017), places where cross-cutting and chronic dimensions of violence, like illicit markets, unemployment, economic disparities between regions, marginalisation, displacement, exploitation, conflicts over local issues, lack of access to public services (e.g. health, infrastructures), and corruption increase risks and the duration of conflicts (Sánchez-Zamora et al. 2017; Flores and Vargas 2018). Yet, health, humanitarian, and cooperation strategies should be stimulated simultaneously to sustain the most vulnerable during the pandemic - like displaced populations- to both the virus itself and those measures enacted to fight it (San Lau et al. 2020).

The forthcoming COVID-19 depression could result in funding cuts to peace operations, endangering their ability to achieve benchmarks, while hampering critical peacebuilding actions like the protection of civilians, protection of social leaders, financial support to ex-combats, and the protection of key infrastructure (Garzón et al. 2020). Reduced funding can also affect local organizations based on projects. Furthermore, the shrinking of peace related budgets limits CDP capacity to hire highly-qualified personal if not keep pre-COVID-19 personnel employed. CDP support to governments, institutions, and conflict parties is likely to be limited in the mid- to long-term (de Coning 2020; Dorussen 2020). At the administrative level, COVID-related constraints oblige peacebuilding CDP organizations to shift to an "essential" frame of mind, forcing a re-examination of activities and interventions, while identifying new threats developing alongside the pandemic and evolving governmental measures. This is challenging due to the multiple and changing faces of the COVID-19 pandemic. Among other aspects, coordinating activities is difficult due to poor internet access, low penetration of mobile networks, electricity cuts, and digital illiteracy in conflict-affected rural areas. In this context, additional funds are being requested to invest in online communication and information systems (Ansorg and Strasheim 2020).

In Colombia, the COVID-19 pandemic is worsening the underlying roots of conflicts, especially in rural contexts beset with unsecure land distribution, poor access to public services, and high levels of inequalities (Peace Direct 2020). In some places, physical and psychological violence is increasing, especially against social, indigenous and environmental leaders, former guerrillas and Venezuelan migrants (Sandoval et al. 2020). Besides, public health measures, including social distancing, lockdowns, and public virtual attendance, trigger delays, slowing the implementation of the 2016 peace agreement between Colombia's government and the Revolutionary Armed Forces of Colombia (FARC). Two immediate consequences exist: First, scarce human and financial governmental capacities show that they are failing to control and monitor isolated and remote regions endowed with natural resources. This not only facilitates the expansion of the drug trafficking business, but is also multiplying practices of violence such as forced recruitment, displacement, land grabbing, and deforestation (Garzón et al. 2020). Second, the COVID-19 outbreak reveals emerging obstacles to the effective implementation of governmental peacebuilding strategies, such as the Programs of Development with a Territorial Focus or Programas de Desarrollo con Enfoque Territorial (PDET) or the Municipal and Departmental Development Plans (rural roads, productive and community infrastructure, schools, health facilities, etc.). The lack of funding, the low degrees of political 
and policy processes at the regional and local level, methodological inconsistencies in the design of participatory approaches and the increased violence against community leaders are preventing the effective implementations of these programs and their cooperation with CDPs.

Notwithstanding these developments, COVID-19 also provides opportunities to promote peace and to advance peacebuilding. Examples include the global ceasefire campaigns (United Nations Press 2020), the immediate impacts on environmental and climate change resulting from lockdowns (e.g. exceptional drops in carbon dioxide emissions) (Eufemia and Hussein 2020), community-based initiatives (e.g. indigenous COVID-19 prevention and containment, focusing on voluntary collective isolation and contact-tracing) (Kaplan et al. 2020), reorientation of ex-guerrilla combatants' productive projects (e.g., from textile production to mask manufacturing), and the use of ICT in transitional justice processes (UN 2020). Although the veracity, impact, and transferability of these advances is unclear, the visible manifestation of the COVID-19 crisis in post conflict scenarios reflect increased complexities and changes in peacebuilding scenarios that also affect the planning and functioning of CDPs.

By investigating the key challenges and coping strategies of implementing agencies and stakeholders to COVID-19, the main aims of this work are to find (i) how CDPs adapt to perceived risks, central government management plans, and funding agency requirements; and (ii) which impact the pandemic has on peacebuilding and corresponding CDP responses. In the following sections, we present our methodology formed by the case study areas and the semi-structured interviews, the results visualizing the main findings, followed by the discussion that addresses key insights against the current situation of both the peacebuilding endeavour and the COVID-19 crisis. Finally, the conclusion summarizes the whole content and it offers suggestions to improved risk-adapted strategies.

\section{Methodology}

\subsection{Case study areas}

Since the 2016 peace agreement, Colombia's peacebuilding process has experienced numerous and complex challenges and changes of power structures regarding land use and ownership; resulting risks include the strengthening of old and new armed groups (Graser et al. 2020). For this reason, our methodological take includes territoriality, as we develop a visualization of conflict-affect areas. We investigate the impact of the COVID-19 crisis on national and international CDPs, targeting projects in some of the most conflict-affected and vulnerable areas of Colombia. Fig. 1 overlays the "Areas Most Affected by Armed Conflict" (ZOMAC), as listed in governmental decree n. 1650 on October 9, 2017 (Republic of Colombia 2017), with the applied 10 surveys, addressing 13 CDPs implemented across multiple regions as shown by dots (a complete list is in the Appendix), including 7 large (with a budget of over 1 million $€$ ), 3 medium (with a budget less than 1 million $€$ and 
Fig. 1 ZOMAC and applied surveys. (Source: Adapted from (C) ZOMAC, Sistema Informativo del Gobierno de la Republica de Colombia-SIG)

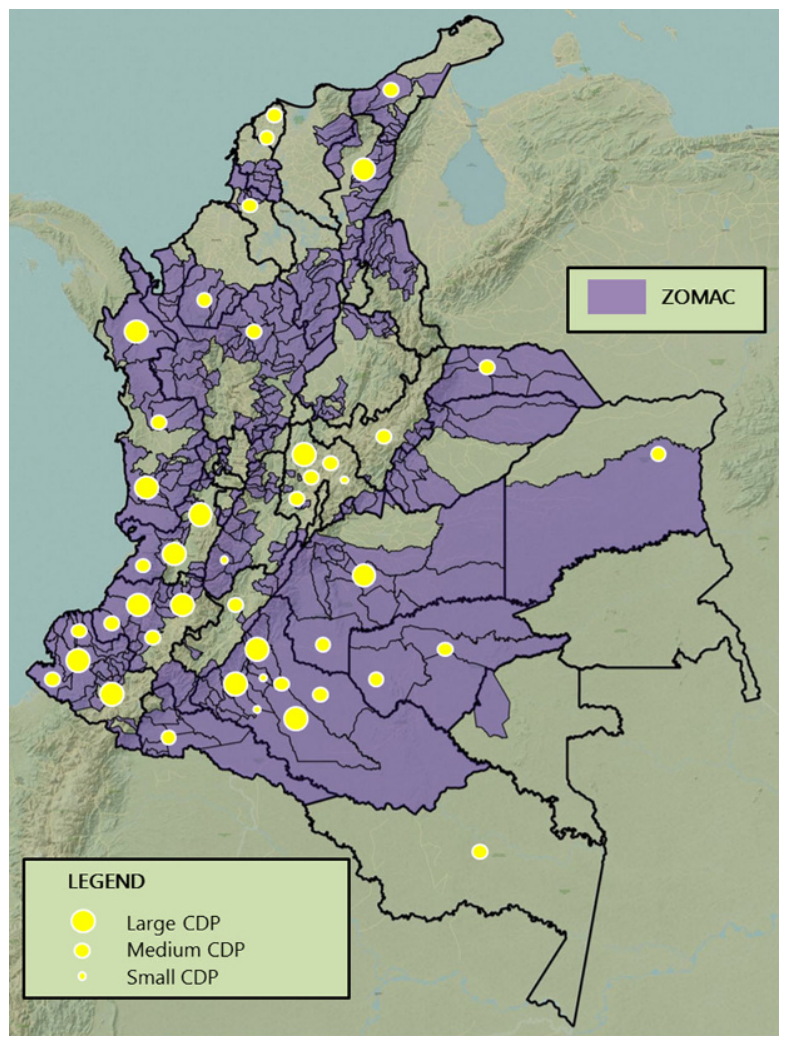

implemented at a national scale), and 3 small (with a budget less than 1 million $€$ and implemented at a local scale) projects.

\subsection{Semi-structured interviews}

A list of running CDPs was obtained through internet and institutional networks. Emails and phone calls with key actors evaluated their willingness to participate. An interview protocol was developed to guide semi-structured interviews with project managers and stakeholders of Colombian CDPs. The questionnaire comprises four main blocks: (i) context: expertise (e.g. peace-related, national, and international) gender, and age; (ii) information about the reference CDP: scale (e.g. local, regional, or national), duration, approximate funding, project role, and project team; (iii) the perceived impact of COVID-19 on project implementation: immediate perception of issue extent, proximity, immediate responses, first effects, and perception regarding governmental responses at all levels (local, regional, and national), as well as of funding agencies and direct donors; and (iv) risk-adapted strategies: evaluation of existing strategies, adoption of new strategies and assets, and the future outlook on desirable risk-adapted strategies. Survey participation was voluntary and personal data kept anonymous. 


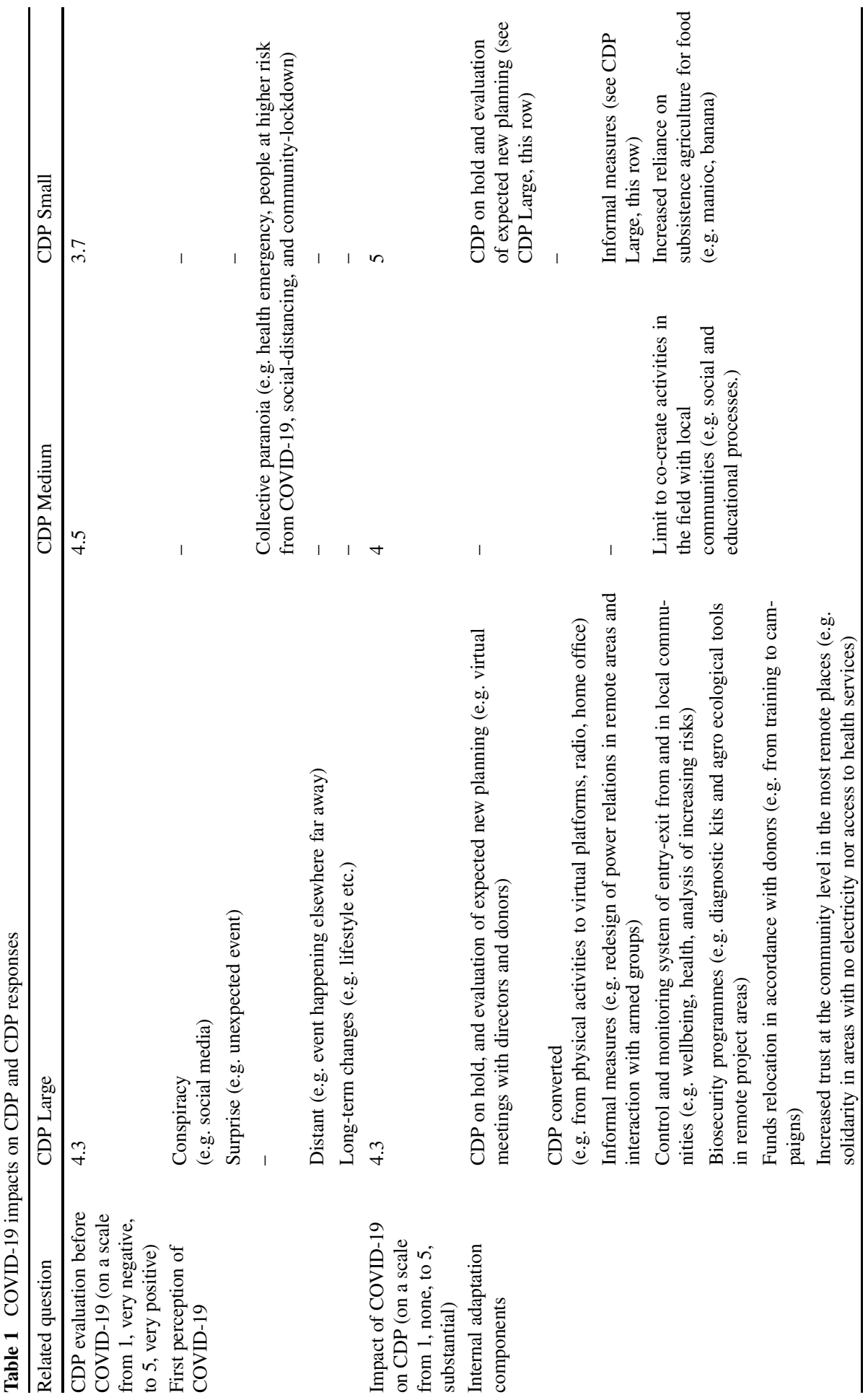




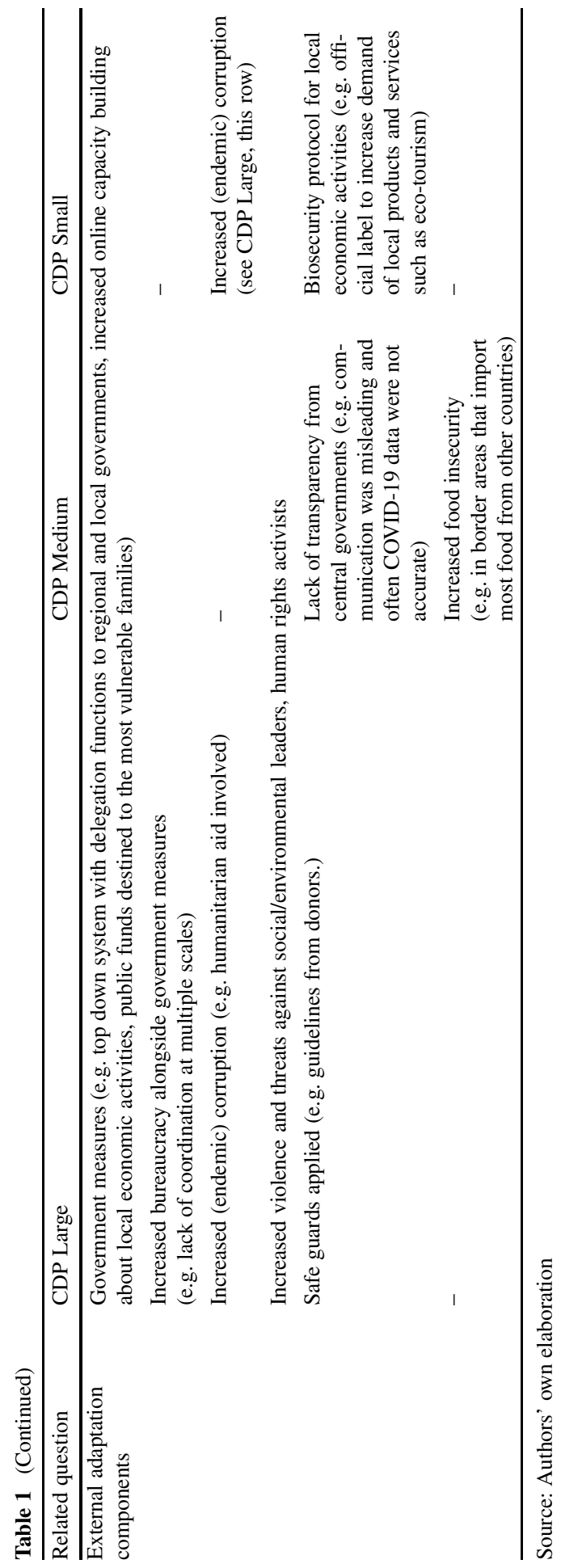




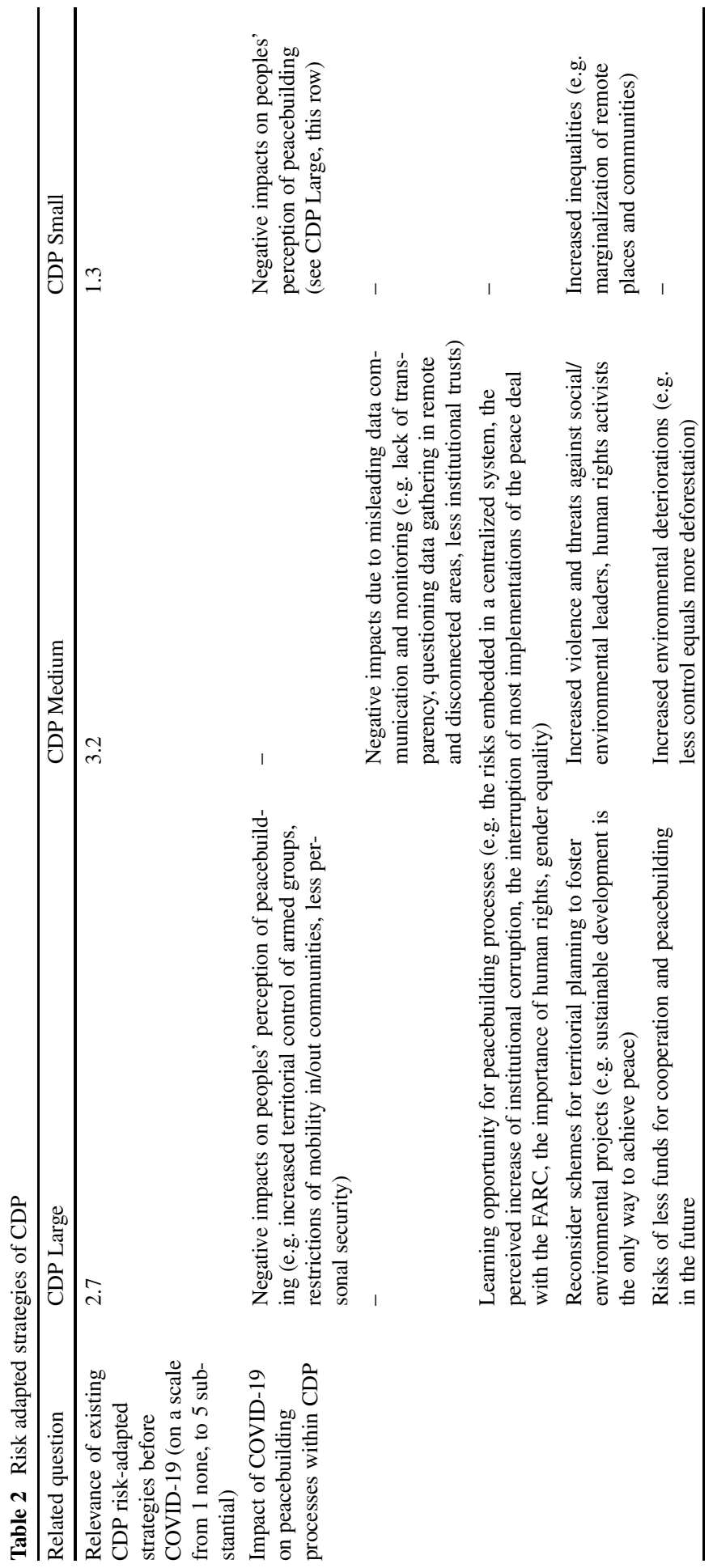




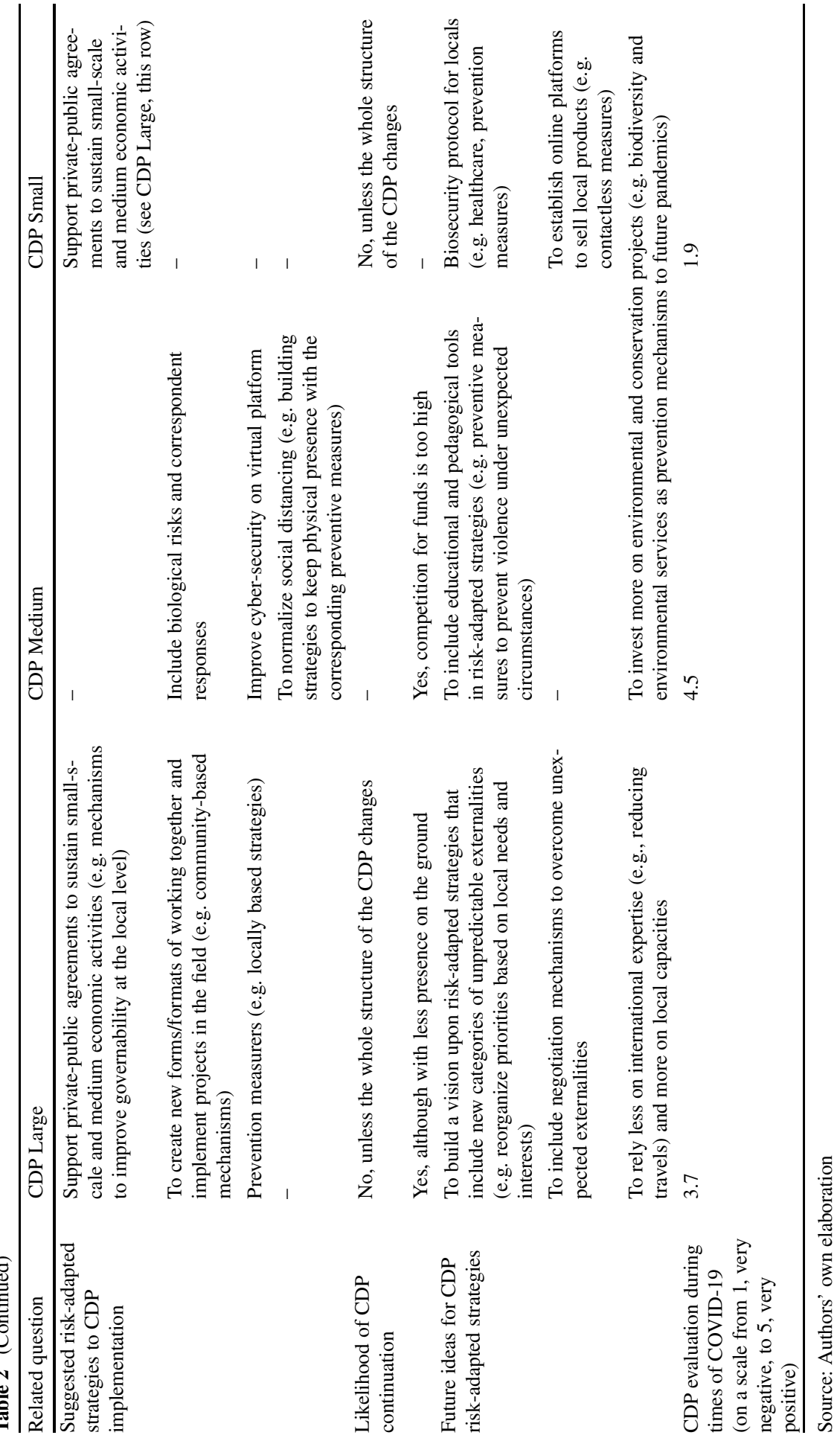


While using qualitative methods to categorize each block, quantitative approaches were used for descriptive statistics to present numeric values. In total, 10 interviews were conducted, addressing the work of $13 \mathrm{CDPs}$, covering most ZOMAC. The interviews were conducted in Spanish via phone or skype, each lasting between forty-five minutes and two hours. Each interview was recorded for further data analysis.

\section{Results}

Relevant findings concerning COVID-19 impacts, CDP responses, and risk-adapted strategies are collected in blocks (iii) and (iv) of the survey (see 2.2 Methods, Step 2. Survey). Tables 1 and 2 present the key interfaces and relations. Grey boxes indicate overlapping perceptions between large, medium, and small CDPs.

\section{Discussion}

The analysis of CDP responses and risk-adapted strategies offers critical perspectives about peacebuilding. In discussing survey results, we highlight key challenges and coping strategies of implementing agencies and stakeholders. Using peacebuilding theories, we focus on specific world experiences (e.g., COVID-19) and its aspects (Heft 1997). Sample composition—affect by finite time and financial capacity-is the main study limitation. Only a few medium and small CDPs were involved. Additionally, with the continuous development of the pandemic, perceptions are changing rapidly. Thus, the results may be biased. Another possible limitation relates to the degree to which our analysis tends to generalize. For example, most of our data regards local perspectives and sample size is small. Thus, results might not translate or be transferrable to a broader context. A larger sample size across more regions, a more heterogeneous set of stakeholders, and the inclusion of donors' perspectives could have strengthened this work.

The perspectives and approaches of implementing agencies and stakeholders show similarities and differences. Our findings show universally substantial impacts of COVID-19 on CDPs. While project self-evaluation remains positive before and during the pandemic for large and medium CDPs, small CDPs are negatively affected. Further, the initial perceptions of large and medium CDPs included elements of surprise and scepticism, while small CDPs responded with immediate collective paranoia, especially with respect to the health emergency. Because COVID-19 stands out for its speed of spread, driven by today's global society, remote rural communities, where small CDPs are implemented, may feel more exposed due to its lack of health services and infrastructure. Historically, poor law-implementation, limited state presence, weak implementations of conflict-prevention measures (e.g. conflict early warning and response mechanisms), high corruption, and inequitable access to services and resources are conditions that make addressing COVID-19 even more challenging (Jayawickreme et al. 2017; Quinn 2016; Rossi et al. 2006). Ultimately, 
globalization's negative consequences primarily affect the poor and marginalized in developing countries (Jenkins 2005).

As a result, internal adaptation plans included both the interruption, in some cases preventatively (e.g. small CDPs), and/or the transformation of CDP. Under COVID19 , most projects shifted field activities from physical to virtual. While, some cases demonstrate how CDPs in rural areas can transform and continue, supported by governmental incentives, social cohesion and new conflicts may arise from "digital fatigue", electricity cuts, and the lack of internet access. Although increased misinformation sharing is a problem rooted in increased internet access, mental disorders are also caused by physical distancing and social/community isolation (Burgess and Fonseca 2020; Islam et al. 2020; Monteith et al. 2020).

Informal measures are re-shaping power relations at the local level with the rise of new and old armed groups contending territorial control (e.g. access entry-exit). Paramilitary and criminal groups are expanding their influence in rural areas, further exploiting natural resources and pursuing illicit activities (e.g. drug production). With the excuse of lockdowns, the consolidation of territorial control increases the vulnerability of civil society and, in particular, those in indigenous communities (Sandoval et al. 2020). Two aspects of trust are emerging: a renewed internal trust in rural community (e.g. solidarity) and a decreasing trust toward institutions and their measures. The latter represent external adaptation components that continue to be enacted. CDPs perceive a top down, central system that delegates functions to regional and local governments, providing funding to assist the most vulnerable communities. In most cases, actions promoted by the central government are perceived negatively, increasing bureaucracy that overlaps with perceived increases in (institutional) corruption, environmental deterioration, food insecurity, human rights violations, and violence against social and environmental leaders.

While large CDPs have greater financial and human capacities to meet such challenges, relocate funds, and implement biosecurity programs, especially in rural contexts, great resilience is also shown by medium and small CDPs, which find creative ways to cope with reduced field activities. Yet, government responses actually increase the complexity of the emergency situation by adding multiple challenges that directly affect the peace, thus hindering direct and indirect protection mechanisms against violence.

Because of lockdown, social alienation might be the main component undermining CDP peacebuilding efforts. Empirical studies show that COVID-19 lockdown measures are affecting mental health and collective trauma (Montoya 2020; Van Bavel et al. 2020); especially problematic for existing post conflict communities. Further, COVID-19 is perceived as negatively affecting Colombian peacebuilding. These challenges and changes in power relations reflect a centralized system unable to support those who are most marginalized, threating CDPs located in rural, remote areas.

Most CDPs are optimistic about the continuation of activities and funds for development and cooperation. Small CDPs are less optimistic, since they face new structural approaches for project implementation. Our findings show that, in times of emergency, learning opportunities arise. First, schemes for territorial planning to foster environmental projects need reconsideration. An increasing literature argues 
that sustainable development is the only way to achieve long lasting peace (Holden et al. 2017; Mansell and Tremblay 2013; Rieckmann 2017). Second, in facing the forthcoming COVID-19 depression, investments in private-public cooperation to sustain small- and medium-scale economic activities is needed, especially in rural areas. Third, strategies for preventing and controlling future pandemics are needed.

Future ideas for CDP risk-adapted strategies include creating new categories of unpredictable externalities (e.g. reorganize priorities based on local needs and interests), educational and pedagogical tools, as well as specific biosecurity protocols for locals. From a local perspective, increasing investments in environmental and conservation projects (e.g. biodiversity and environmental services as prevention mechanisms to future pandemics) is perceived as a key coping strategy that encourages peacebuilding and the implementation of CDPs in times of unexpected externalities.

Finally, the development of project strategies that address risks and uncertainty can be better guided by social learning processes. In this sense, social learning facilitates the integration of different kinds of knowledge (Wals 2007), especially when collectively deciding on actions to cope with crisis situations, unpredictable externalities, or future uncertainty. As proposed by Morin (2002), learning to confront uncertainty is essential knowledge for the future.

\section{Conclusions}

This work highlights key challenges and coping strategies of implementing agencies and stakeholders during the COVID-19 pandemic. The increasing complexity caused by top down governmental measures, effective or not, along with the rise of new local level power relations (e.g. armed groups, illicit activities, environmental deterioration etc.) and social alienation are negatively affecting peacebuilding in Colombia. Remote rural communities (e.g. where small CDPs are implemented) are the most exposed due to the lack of infrastructure (e.g. health services, presence of the state, electricity etc.) and their historic vulnerability (in case they are economically autonomous). Further, the increasing erosion of trust between locals and institutions, along with food insecurity and expected unemployment scenarios due to the COVID-19 depression will not only increase the risk of violence and social unrest, but also the survival of CDPs. In the midst of a crisis, policies and economic efforts should target rural contexts, where peace is most at stake; supporting initiatives historically carried by CDPs such as ceasefires, the mutual assistance and intercommunity cooperation; thus preventing immediate violence and contributing to a construction of more lasting peace in the future. While investments in privatepublic cooperation and in environmental projects are perceived as key coping strategies against COVID-19, future implications for peace and peacebuilding remain unclear. Thus, further research and monitoring approaches are needed.

Acknowledgements We thank all participating project managers and stakeholders. This research is supported by the project "Implementing sustainable agricultural and livestock systems for simultaneous targeting of forest conservation for climate change mitigation (REDD+) and peace-building in Colombia", which is part of the International Climate Initiative (IKI). The Federal Ministry for the Environment, Na- 
ture Conservation and Nuclear Safety (BMU) supports this initiative on the basis of a decision adopted by the German Bundestag (https://www.international-climate-initiative.com/).

Funding Open Access funding enabled and organized by Projekt DEAL.

Open Access This article is licensed under a Creative Commons Attribution 4.0 International License, which permits use, sharing, adaptation, distribution and reproduction in any medium or format, as long as you give appropriate credit to the original author(s) and the source, provide a link to the Creative Commons licence, and indicate if changes were made. The images or other third party material in this article are included in the article's Creative Commons licence, unless indicated otherwise in a credit line to the material. If material is not included in the article's Creative Commons licence and your intended use is not permitted by statutory regulation or exceeds the permitted use, you will need to obtain permission directly from the copyright holder. To view a copy of this licence, visit http://creativecommons.org/licenses/by/4. $0 /$. 


\section{Appendix}

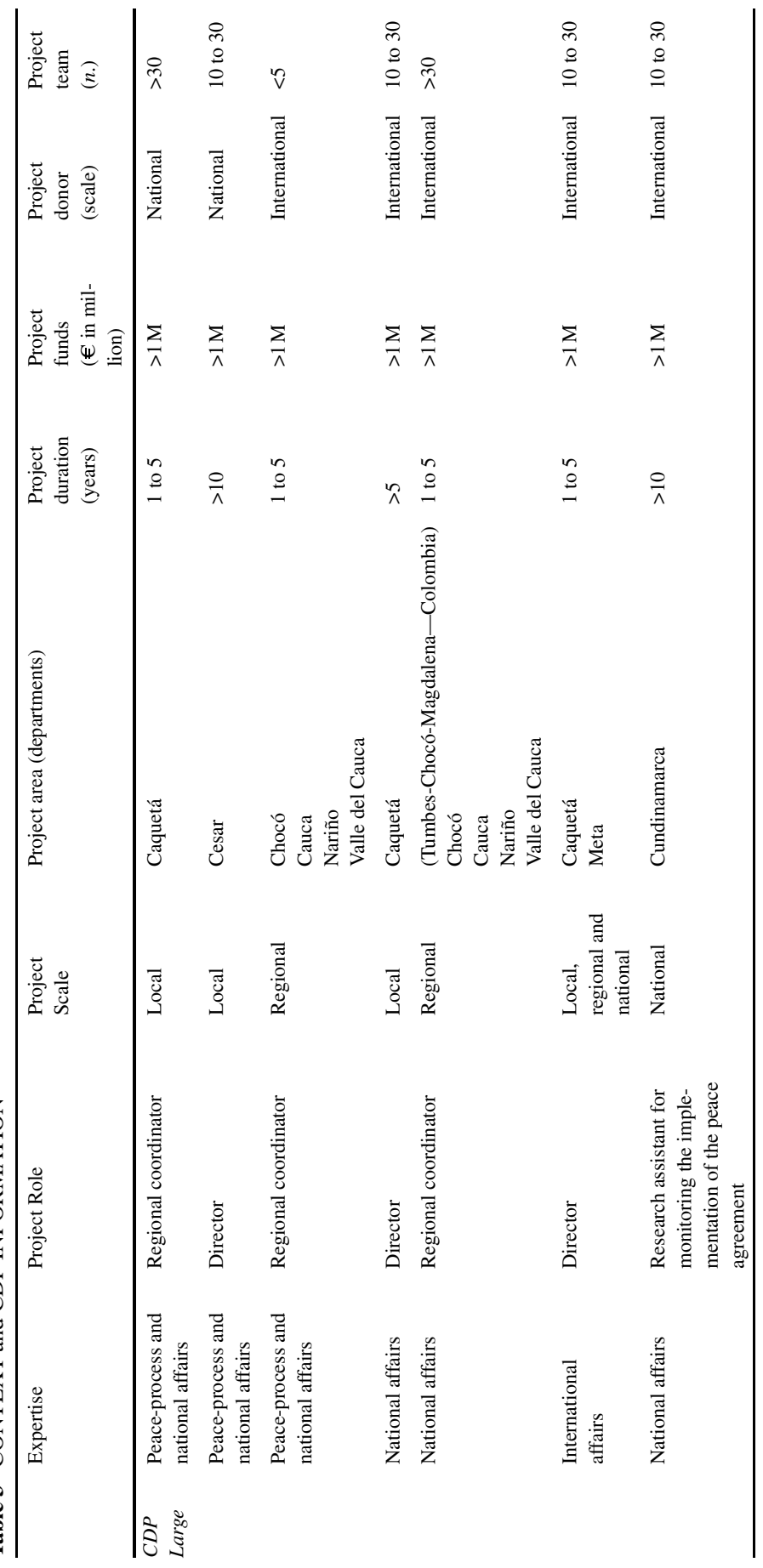




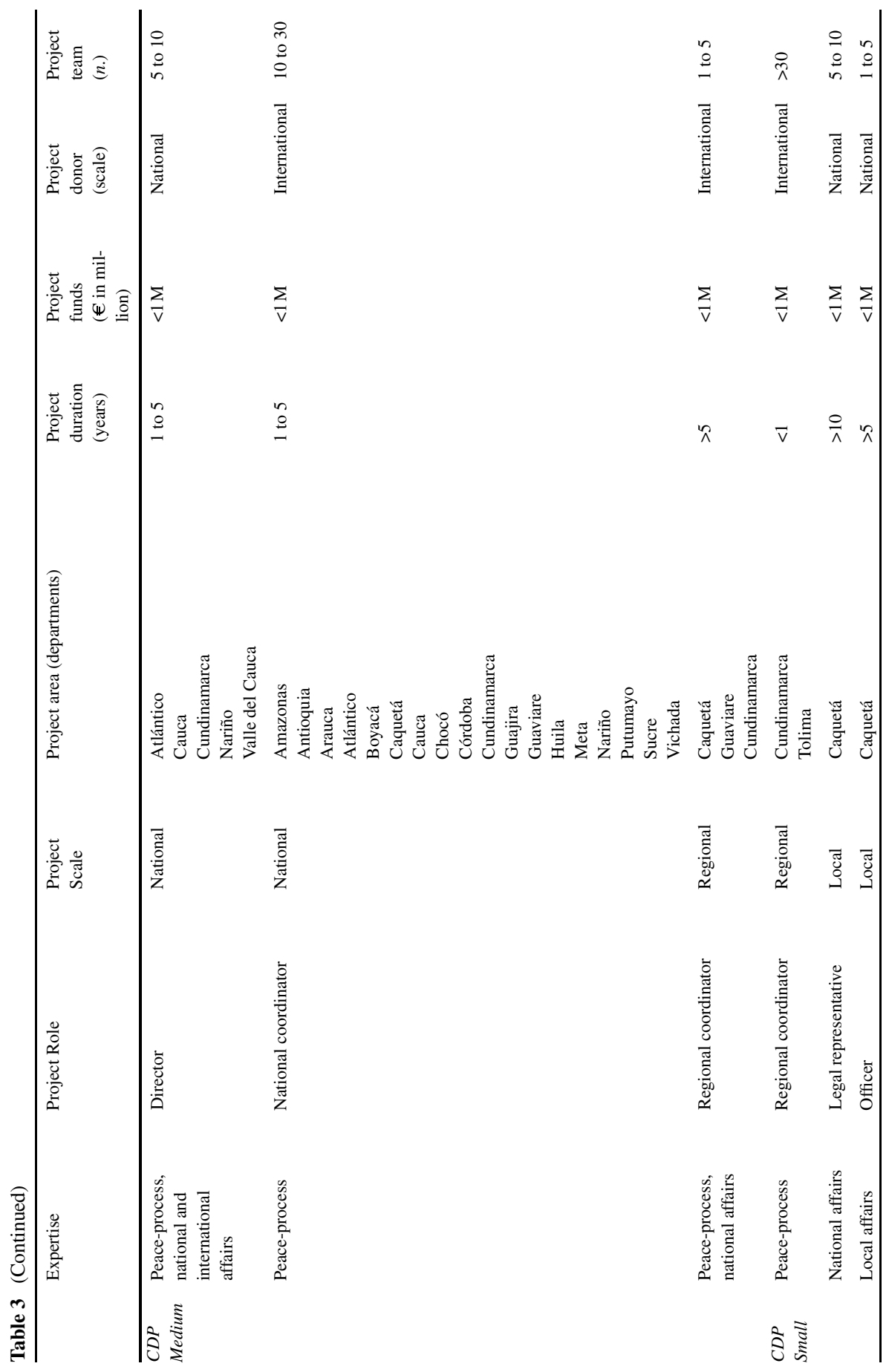




\section{References}

Amego Korbla Penu, D., and D. Wellington Essaw. 2019. Geographies of peace and violence during conflict: the case of the Alavanyo-Nkonya boundary dispute in Ghana. Political Geography 71:91-102.

Ansorg, N., and J. Strasheim. 2020. COVID-19 is a window of opportunity for Peacebuilding-use it!, peacelab-Blog. https://peacelab.blog/2020/04/covid-19-is-a-window-of-opportunity-for-peace building-use-it. Accessed 16 June 2020.

Bavel, J. J. V., K. Baicker, P. S. Boggio, V. Capraro, A. Cichocka, M. Cikara, et al. 2020. Using social and behavioural science to support COVID-19 pandemic response. Nat Hum Behav 4(5):460-471. https:// doi.org/10.1038/s41562-020-0884-z.

Burgess, R.A., and L. Fonseca. 2020. Re-thinking recovery in post-conflict settings: supporting the mental well-being of communities in Colombia. Global Public Health 15(2):200-219.

De Coning, C. 2020. The impact of COVID-19 on the performance of peace operations. COVID-19 BRIEF. Oslo: NUPI Norwegian Institute of International Affairs.

Dorussen, H. 2020. Peacekeeping after Covid-19. Peace Economics, Peace Science and Public Policy 2:1-9. https://doi.org/10.1515/peps-2020-0022.

Eufemia, L., and H. Hussein. 2020. How did the COVID-19 crisis relate to meeting global climate targets for 2020? Future of Food: Journal on Food, Agriculture and Society 8:2.

Fischhendler, I., and K. Tenenboim-Weinblatt. 2019. The peace dividend as an intangible benefit in megaproject justification: a comparative content analysis of the Dead Sea-Red Sea Canal. Geoforum 101:141-149.

Flores, T.E., and J.F. Vargas. 2018. Colombia: Democracy, violence, and the peacebuilding challenge. Conflict Management and Peace Science 35(6), 581-586. https://doi.org/10.1177/0738894218787786.

Garzón, J.C., I. Cuesta, T. Prada, C. Riveros, Á. Silva, P. Tobo, A. Durán, et al, 2020. Impactos y riegos del COVID-19 en la paz y las dinámicas del conflicto. https://doi.org/10.1017/CBO9781107415324. 004. http://www.ideaspaz.org/publications/posts/1816

Graser, M., M. Bonatti, L. Eufemia, H. Morales, M. Lana, K. Löhr, and S. Sieber. 2020. Peacebuilding in rural colombia - a collective perception of the integrated rural reform (IRR) in the department of Caquetá (Amazon). Land 9(2):36.

Heft, Harry. 1997. The relevance of Gibson's ecological approach to perception for environment-behaviour studies. In Toward the integration of theory, methods, research, and utilization, Vol. 4, ed. Gary T. Moore, Roberto W. Marans, 71-108. Boston: Springer.

Holden, E., K. Linnerud, and D. Banister. 2017. The imperatives of sustainable development. Sustainable Development 25(3):213-226.

Islam, A.N., S. Laato, S. Talukder, and E. Sutinen. 2020. Misinformation sharing and social media fatigue during COVID-19: An affordance and cognitive load perspective. Technological Forecasting and Social Change 159:120201.

Jaruma, B. 2013. The effective framework of the rule of law for peace building and security. Procedia-Social and Behavioral Sciences 91(2013):105-112.

Jayawickreme, N., C. Mootoo, C. Fountain, A. Rasmussen, E. Jayawickreme, and R.F. Bertuccio. 2017. Post-conflict struggles as networks of problems: A network analysis of trauma, daily stressors and psychological distress among Sri Lankan war survivors. Social Science \& Medicine 190:119-132.

Jenkins, Rhys. 2005. Globalization, production and poverty. The Impact of Globalization on the World's Poor. Palgrave Macmillan, London, 163-187.

Kaplan, H.S., B.C. Trumble, J. Stieglitz, R.M. Mamany, M.G. Cayuba, L.M. Moye, R.C. Thompson, et al, 2020. Voluntary collective isolation as a best response to COVID-19 for indigenous populations? A case study and protocol from the Bolivian Amazon. The Lancet 395(10238):1727-1734.

San Lau, L., G. Samari, R.T. Moresky, S.E. Casey, S.P. Kachur, L.F. Roberts, and M. Zard. 2020. COVID19 in humanitarian settings and lessons learned from past epidemics. Nature Medicine 26(5):647-648.

Lemon, A., and M. Pinet. 2018. Measuring unintended effects in peacebuilding: what the field of international cooperation can learn from innovative approaches shaped by complex contexts. Evaluation and Program Planning 68(2018):253-261.

Mansell, R., and G. Tremblay. 2013. Renewing the knowledge societies vision for peace and sustainable development. Paris: UNESCO. https://unesdoc.unesco.org/ark:/48223/pf0000224531.

Monteith, L.L., R. Holliday, T.L. Brown, L.A. Brenner, and N.V. Mohatt. 2020. Preventing suicide in rural communities during the COVID-19 pandemic. The Journal of Rural Health 00:1-6. https://doi.org/ $10.1111 /$ jrh. 12448 . 
Montoya, V. 2020. Confinamiento/aislamiento: del lenguaje preventivo del COVID-19 a la pragmática de la guerra en Colombia. Geopolítica(s). Revista de estudios sobre espacio y poder 11(Especial):285-291.

Moore, M., B. Gelfeld, C.P. Adeyemi Okunogbe, and C. Paul. 2017. Identifying future disease hot spots: infectious disease vulnerability index. Rand health quarterly 6(3):5.

Morin, E. 2002. Seven complex lessons in education for the future. UNESCO. https://unesdoc.unesco.org/ ark:/48223/pf0000123074. Accessed 4 Aug 2020.

Peace Direct. 2020. COVID-19 and the impact on local peacebuilding. https://www.peacedirect.org/wpcontent/uploads/2020/04/COVID-19-and-the-impact-on-local-peacebuilding.pdf. Accessed 14 June 2020.

Quinn, M. 2016. Governance and health in post-conflict countries: the Ebola outbreak in Liberia and Sierra Leone. New York: International Peace Institute.

Republic of Colombia. 2017. Decreto 1650, 09/10 2017-Presidencia de la República de Colombia. http://es.presidencia.gov.co/normativa/normativa/DECRETO\%201650\%20DEL\%2009\%20DE \%20OCTUBRE\%20DE\%202017.pdf. Accessed 22 June 2020.

Rieckmann, M. 2017. Education for sustainable development goals: learning objectives. Paris: UNESCO Publishing. https://www.unesco.de/sites/default/files/2018-08/unesco_education_for_sustainable_ development_goals.pdf.

Rossi, L., T. Hoerz, V. Thouvenot, G. Pastore, and M. Michael. 2006. Evaluation of health, nutrition and food security programmes in a complex emergency: the case of Congo as an example of a chronic post-conflict situation. Public health nutrition 9(5):551-556.

Sánchez-Zamora, P., R. Gallardo-cobos, and C. Romero-Huertas. (2017). Assessing the determinants of territorial cohesion: Evidence from Colombian departments. Geoforum, 87:48-61. https://doi.org/10. 1016/j.geoforum.2017.10.004.

Sandoval, C., M. Cruz, and C. Ruiz. 2020. Victims' participation in times of Covid-19 in transitional justice accountability mechanisms: what is needed for virtual hearings to fulfil this right? The case of Colombia and the special jurisdiction for peace. In Covid-19, law and human rights: essex dialogues, 73-81. https://doi.org/10.5526/xgeg-xs42.

UN. 2020. "Comunicado de prensa de la misión de verificación de la onu en colombia. https://colombia. unmissions.org/comunicado-de-prensa-de-la-misi\%C3\%B3n-de-verificaci\%C3\%B3n-de-la-onuen-colombia- 0 . Accessed 20 June 2020.

UNDP. 2020. Tailoring the socioeconomic response to COVID-19 in peacebuilding contexts. https://www. undp.org/content/undp/en/home/news-centre/speeches/2020/ambassadorial-level-meeting-of-thePBC.html. Accessed 16 June 2020.

United Nations Press. 2020. UN Secretary-General renews appeal for Global Ceasefire, 2020. https://unric. org/en/un-secretary-general-renews-appeal-for-global-ceasefire/. Accessed 16 June 2020.

Wals, A.E. (ed.). 2007. Social learning towards a sustainable world: principles, perspectives, and praxis. Wageningen: Wageningen Academic Publishers. 